\title{
Association between Delay in Surgical Treatment and Perforation in Acute Appendicitis
}

\author{
Koyuncu A, Yavuz A*, Buluş H and Doğan M
}

Kecioren Resarch and Training Hospital, General Surgery Department, Ankara, Turkey

*Corresponding author: Yavuz A, Kecioren Resarch and Training Hospital, General Surgery Department, Ankara, Turkey, Fax: +0903123569002, Tel: +0905052771124, E-mail: alperyavuz@hotmail.com

Citation: Koyuncu A, Yavuz A, Buluş H, Doğan M (2016) Association between Delay in Surgical Treatment and Perforation in Acute Appendicitis. J Surg Oper Care 1(2): 205. doi: 10.15744/2455-7617.1.205

Received Date: January 15, 2016 Accepted Date: May 09, 2016 Published Date: May 11, 2016

\begin{abstract}
Introduction: Acute appendicitis is a prevalent emergency surgical pathology and without prompt intervention may lead to gangrene, perforation and death. Increased mortality and morbidity will increase the hospital stay and the costs. We aimed to see the association between surgical treatment and perforation.

Patient and Method: 130 patients who were undergone emergency appendectomy were included in the study. Patients were divided into three groups based on the time from symptom onset to the operation (Group 1, <24hours; Group 2, 24-36 hours; Group 3, >36 hours). Perforation rates, surgical site infections, operation time and hospital stay was compared.

Result: Hospital stay was shorter in Group 1 compared to Group 2 and 3 and were respectively 1.9 days, 3.4 days, 4.8 days. Surgical site infection was $5.4 \%$ for Group 1, 7.2\% for Group 2, $10 \%$ for Group $3(\mathrm{p}<0.02)$. When the perforation rate was compared it was found $3 \%$ for group 1, 13\% for Group 2, 31\% for Group 3 and it was statistically significant $(\mathrm{p}<0.001)$.

Conclusion: Surgical site infections, hospital stay, perforation and complications associated with perforation were less in patients with acute appendicitis who were diagnosed and treated within 24 hours of symptom onset than patients who were diagnosed after 24 hours.

Keywords: Acute appendicistis; Appendectomy; Delay in surgery; Perforation rate
\end{abstract}

\section{Introduction}

Appendicitis is the most common nonelective procedure performed by general surgeons [1]. It has generally been accepted that an appendectomy should be performed within a few hours of diagnosis and that a delay in the operation may lead to an increase in the morbidity [2-4]. Appendiceal rupture puts patients at risk for serious sequelae including peritonitis, sepsis and death. Increasing time between symptom onset and treatment may be a risk factor for a ruptured appendix, but little is known about how the risk changes with passing time. Most studies assessing the effect of time between symptom onset and treatment on risk of appendiceal rupture compare ruptured and nonruptured groups [3-5].

This study aimed to determine the changes in risk of rupture in patients with appendicitis with increasing time from symptom onset to treatment to help guide the swiftness of surgical intervention.

\section{Patient and Method}

130 patients (female/male 34/96) between 16 and 65 ages who were undergone emergency appendectomy in a 12 months period in Keçiören Education Hospital General Surgery Clinic were included in the study. In this period 157 patients had appendectomy but 27 of these who didn't meet the inclusion criteria were excluded. All patients had classic (open) appendectomy. Patients were divided into three groups based on the onset of sypmtoms. Group 1, patients operated in 24 hours; Group 2, patients operated between 24-36 hours; Group 3, patients operated after 36 hours.

Patients who were undergone laparascopic appendectomy, interval appendectomy under 16 years old, older than 65 years, diabetes, malignant disease, immune supression and antibiotic usage were excluded.

Patients admitted to the emergency department were first evaluated by emergency resident. In case of suspected appendicitis they were evaluated by a general surgeon in the emergency ward. Clinical data, physical examination, laboratory and imaging studies were the mainstays of evaluation. Patients who were diagnosed acute appendicitis and patients who underwent clinical observation were included. Symptom onset and leukocyte counts operation start and end time were recorded. Hospital stay defined as arrival at hospital to discharge of patient. Perforation defined as opening the appendiceal lumen macroscopically. Surgical site infection 
defined as presence of clinically or microbiological infection. All of the diagnoses and perforations were histopathologically confirmed. Perforation rates, surgical site infections and hospital stay was compared.

SPSS software was used for the statistical analysis. The $\mathrm{x} 2$ test and ANOVA were used to analyze the statistical difference between the 2 groups. A P value of less than 0.05 was considered significant.

\section{Results}

A total of 130 appendicectomies were performed in patients aged 16 to 65 years in the 12-month period from September 2006 to 2007. The average age of these patients was 32.8 years (range 16-65 years). There were 96 men and 34 women in the study group. $33(25.3 \%)$ of the 130 patients were Group 1, 67 (51.5\%) of the 130 patients were Group 2 and 30 (23\%) of the 130 patients were Group 3 (Table 1).

\begin{tabular}{|c|c|c|c|c|}
\hline & $\begin{array}{c}\text { Group I } \\
(\mathbf{n = 3 3})\end{array}$ & $\begin{array}{c}\text { Group II } \\
(\mathbf{n = 6 7 )}\end{array}$ & $\begin{array}{c}\text { Group III } \\
(\mathbf{n = 3 0 )}\end{array}$ & P value \\
\hline Gender (Female / Male) & $24 / 9$ & $40 / 17$ & $22 / 8$ & $>0.089$ \\
\hline Mean hospital stay (days) & $1.9(1-3)$ & $3.4(1-10)$ & $4.8(2-14)$ & $>0.086$ \\
\hline Operation times (minutes) & $35(30-45)$ & $58(40-65)$ & $69(40-80)$ & $<0.002$ \\
\hline Perforasyon rate & $3 \%(13 / 76)$ & $13 \%(11 / 132)$ & $31 \%$ & $<0.001$ \\
\hline Surcical site infection rate & $5.4 \%$ & $7.2 \%$ & $10 \%$ & $<0.02$ \\
\hline
\end{tabular}

Group 1, patients operated in 24 hours; Group 2, patients operated between 24-36 hours; Group 3, patients operated after 36 hours

Table 1: Outcome of comparison between groups

Perforation rates were 3\% (1 patient) for Group 1 , 13\% (9 patients) for Group 2 and 31\% for Group 3 (10 patients). When Group 1 and others (Group 2,3) were compared it was statistically significant $(\mathrm{p}<0.001)$ but the difference between Group 2 and 3 was not statistically significant.

Hospital stay was shorter in Group 1 than Group 2 and 3, it was 1.9 days, 3.4 days, 4.8 days respectively ( $<0.038$ ). Surgical site infection rate was $5.4 \%$ for Group 1, 7.2\% for Group 2 and $10 \%$ for Group 3 ( $<<0.02$ ). Mean operation time was 35 minutes for Group 1, 58 minutes for Group 2 and 69 minutes for Group 3.

\section{Discussion}

In this study, surgical site infections, hospital stay, perforation and complications associated with perforation were less in patients with acute appendicitis who were diagnosed and treated within 24 hours of symptom onset than patients who were diagnosed after 24 hours.

Acute appendicitis, the term we use today and the pathophysiological abnormality we understand in the 21 st century, is attributed to Reginald H. Fitz [6]. He also recognized the vital importance of early diagnosis and immediate surgical intervention. Appendicitis may mimic other clinical conditions. Inflammatory and infectious disorders such as gastroenteritis and respiratory infections may cause lymphoid follicle hyperplasia, which results in luminal obstruction and appendiceal inflammation [7]. Acute appendicitis is typically done within hours of diagnosis to prevent the complications of gangrene and perforation. In uncertain cases, delay of surgery and repeated assessment are commonly practised to achieve a more precise diagnosis. All these factors may contribute to diagnostic or therapeutic delays in the management of acute appendicitis. Delay in treatment is regarded as the main cause of perforation and complications, but there are controversies as to whether preadmission or postadmission delay is more important [8-10]. Fortunately, death due to acute appendicitis is now rare (mortality rate, $0 \%-2.4 \%$ ) [9-14]. Nevertheless, failure to diagnose appendicitis early is still a leading cause of increased perforation and complications (complication rate, 3.4\%-33\%) [3,15,16].

One of the most prominent changes that marked the last few years has been the emphasis on the potential negative impact of prolonged work hours for residents $[17,18]$. The authors said that it can be helpful to delay in performing an appendectomy for acute appendicitis for 12 to 24 hours after the diagnosis, especially at night so that trainees, surgeons, and other personnel do not lose sleep an important consideration since the complication rates and results of immediate and late appendectomy are the same.

Surana, et al. [4] studied the effects of delaying an appendectomy for acute appendicitis. They found no statistical difference in the rate of complications between children who underwent appendectomies within 6 hours of diagnosis and those who underwent appendectomies between 6 and 18 hours of diagnosis ( $2.3 \%$ to $4.2 \%$, respectively; $\mathrm{P}=0.28$ ). A similar study by Yardeni, et al. [2] on the effects of delaying appendectomies by 6 to 24 hours in children showed no significant increase in the rate perforation, operative time, or complications when compared with children who underwent the appendectomies within 6 hours. Furthermore, some studies suggest that the rate of perforation is due to a delay in patient presentation rather than to a delay in treatment. [18,19]. In our study, the early and late groups had similar clinical outcomes. The group III, group II had more longer length of stay than the group I (4.8 days, 3.4 days, 1.95 days respectively). 
Highest perforation rate was in Group 3 and the difference was statistically significant when compared to Group 1. Surgical site infection rate was alike and for Group 1, Group 2 and Group 3 it was 5.4\%, 7.2\%, 10\% respectively $(\mathrm{p}<0.02)$.

Many retrospective studies do demonstrate a direct relationship between symptom duration and perforation rate, however, these studies do not prospective randomise. Our study was prospective, randomized [20]. We didn't try to find out the reasons for delay and the stage of the disease but the time on which the perforation makes a peak. This study's purpose was to determine the association between increasing time from symptom onset to treatment and risk of rupture in patients with appendicitis. We did not seek to determine the likelihood of an appendicitis diagnosis in patients presenting with abdominal pain, and these data are not applicable to patients without appendicitis. Although this approach limits the applicability of our findings to patients with appendicitis, it provides an important benchmark for physicians treating patients with appendicitis-information that is lacking. Time between symptom onset and treatment, a potentially modifiable factor, is associated with risk of ruptured appendicitis.

Bichell, et al. found out $0-2 \%$ perforation rate for every 12 hours on the first 36 hours, after 36 hours this rate increased to $5 \%$ for every 12 hours [21]. In our study for the first 24 hours perforation rate was 3\%, after that it increased $10 \%$ for every 12 hours.

Maroju, et al. prehospital time was broken down into segments of $12 \mathrm{~h}$ to identify a cut off point beyond which the incidence of perforation increases significantly. Their found that $82 \%$ of the patients who had an acutely inflamed appendix presented within 36 $\mathrm{h}$ of the onset of their symptoms, and $82 \%$ of these patients presented in the first $24 \mathrm{~h} \mathrm{[22].} \mathrm{On} \mathrm{the} \mathrm{other} \mathrm{hand} 75.5 \%$ of advanced appendicitis patients presented at least $36 \mathrm{~h}$ after the onset of complaints, and $45 \%$ of these patients arrived $72 \mathrm{~h}$ after onset [2]. When the total delay in similar time intervals was analysed, it was found that at a delay of more than $36 \mathrm{~h}$ there was a significant increase in the incidence of advanced appendicitis. Colson, et al. found that patients who delayed presenting for more than $12 \mathrm{~h}$ after the onset of symptoms had a higher incidence of perforation $[9,19]$. In our study $77 \%$ of the patients were operated in the first 36 hours of symptom onset. Temple, et al. found out that $20 \%$ of the perforated appendices had a delay of less than $24 \mathrm{~h}$ from the onset of symptoms. While our results were like Colson, et al. they were contradictory to Temple, et al. [20].

Pediatric and geriatric populations are privileged age groups. These cases have sensitive nature regardless of the disease [23,24]. Therefore, we exclude these groups. However, we did not exclude adolescents. Perhaps this is the most serious shortcomings of our work.

In conclusion, morbidity caused by acute appendicitis increases with delay in treatment. Whatever the cause is, when the patients operated on the first 24 hours and others are compared morbidity and hospital stay increases significantly on the latter.

\section{References}

1. Pittman-Waller VA, Myers JG, Stewart RM, Dent DL, Page CP, et al. (2000) Appendicitis: why so complicated? analysis of 5755 consecutive appendectomies. Am Surg 66: 548-54.

2. Yardeni D, Hirschl RB, Drongowski RA, Teitelbaum DH, Geiger JD, et al. (2004) Delayed vs immediate surgery in acute appendicitis: do we need to operate during the night? J Pediatr Surg 39: 464-9.

3. Eldar S, Nash E, Sabo E, Matter I, Kunin J, et al. (1997) Delay of surgery in acute appendicitis. Am J Surg 173: 194-8.

4. Surana R, Quinn F, Puri P (1993) Is it necessary to perform appendicectomy in the middle of the night in children? BMJ 306: 1168.

5. Buckley RG, Distefan J, Gubler KD, Slymen D (1999) The risk of appendiceal rupture based on hospital admission source. Acad Emerg Med 6: 596-601.

6. Fitz RH (1886) Perforating inflammation of the vermiform appendix, with special reference to its early diagnosis and treatment. Trans Assoc Am Physicians 1: $107-44$.

7. Jess P, Bjerregaard B, Brynitz S, Holst-Christensen J, Kalaja E, et al. (1981) Acute appendicitis. Prospective trial concerning diagnostic accuracy and complications. Am J Surg 141: 232-4.

8. Lau WY, Fan ST, Yip WC, Chu KW, Yiu TF, et al. (1987) Acute appendicitis in children. Aust NZ J Surg 57: 927-31.

9. Franz MG, Norman J, Fabri PJ (1995) Increased morbidity of appendicitis with advancing age. Am Surg 61: 40-4.

10. Brender JD, Marcuse EK, Koepsell TD, Hatch EI (1985) Childhood appendicitis: factors associated with perforation. Pediatrics 76: 301-6.

11. Moore SW, Schneider J (1995) Acute appendicitis in childhood: Experience in a developing country. Pediatr Surg Int 10: 71-5.

12. Domeier RM (1996) Acute appendicitis. Foresight 39: 1-5.

13. Webster DP, Schneider CN, Cheche S, Daar AA, Miller G (1993) Differentiating acute appendicitis from pelvic inflammatory disease in women of childbearing age. Am J Emerg Med 11: 569-72.

14. Marchildon MB, Dudgeon DL (1977) Perforated appendicitis: current experience in a children’s hospital Ann Surg 185: 84-7.

15. Schwerk WB, Wichtrup B, Rüschoff J, Rothmund M (1990) Acute and perforated appendicitis: current experience with ultrasoundaided diagnosis. World J Surg 14: 271-6.

16. Rothrock SG, Skeoch G, Rush JJ, Johnson NE (1991) Clinical Features of Misdiagnosed Appendicitis in Children. Ann Emerg Med 20: 45-50.

17. Taffinder NJ, McManus IC, Gul Y, Russell RC, Darzi A (1998) Effect of sleep deprivation on surgeons' dexterity on laparoscopy simulator. Lancet $352: 1191$.

18. Steinbrook R (2002) The debate over residents' work hours. N Engl J Med 347: 1296-302.

19. Colson M, Skinner KA, Dunnington G (1997) High negative appendectomy rates are no longer acceptable. Am J Surg 174: 723-6.

20. Temple CL, Huchcroft SA, Temple WJ (1995) The natural history of appendicitis in adults: a prospective study. Ann Surg 221: 278-81.

21. Bickell NA, Arthur AH Jr, Rojas M, Bodian C (2006) How Time Affects the Risk of Rupture in Appendicitis. J Am Coll Surg 202: 401-6.

22. Maroju NK, Robinson Smile S, Sistla SC, Narasimhan R, Sahai A (2004) Delay In Surgery For Acute Appendicitıs. ANZ J Surg 74: 773-6. 
23. Harris JA (1997) Pediatric Nosocomial Infections: Children Are Not Little Adults. Infect Control Hosp Epidemiol 18: 739-42.

24. Ribas RM, Gontijo Filho PP (2003) Comparing hospital infections in the elderly versus younger adults: an experience in a Brazilian University Hospital. Braz J Infect Dis 7: 210-5

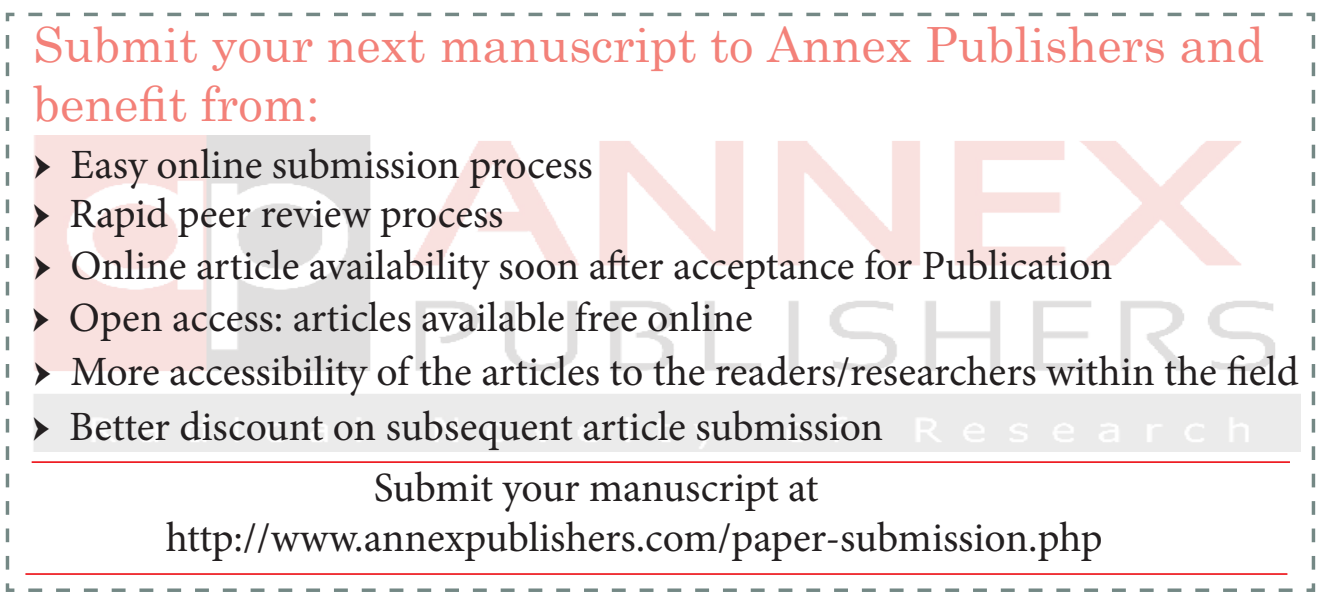

